\title{
The potential developmental programming effect of oral curcumin on the bone health and plasma total osteocalcin of male and female rats fed a high-fructose diet during suckling and post weaning
}

\author{
Kasimu G. Ibrahim ${ }^{1,2}$, Hayley L. Wright ${ }^{1}$, Eliton Chivandi ${ }^{1}$, Michael T. Madziva ${ }^{1}$ and Kennedy \\ H. Erlwanger ${ }^{1}$ \\ ${ }^{1}$ School of Physiology, Faculty of Health Sciences, University of the Witwatersrand, Johannesburg, South Africa \\ ${ }^{2}$ Department of Physiology, Faculty of Basic Medical Sciences, College of Health Sciences, Usmanu Danfodiyo Uni- \\ versity, Sokoto, Nigeria
}

\begin{abstract}
We investigated the effect of oral curcumin on bone health of rats fed a high-fructose diet. Suckling pups (males $=65$, females $=63$ ) were gavaged with $0.5 \%$ DMSO, curcumin $(500 \mathrm{mg} / \mathrm{kg})$, fructose $(20 \%, \mathrm{w} / \mathrm{v})$ or a combination of curcumin and fructose daily from postnatal days 6 to 21 . Then the rats were weaned onto normal rat feed for six weeks and each group was sub-divided into two subgroups: one had plain tap water and the other had fructose $(20 \%$, w/v) to drink. Blood was assayed for plasma total osteocalcin. Morphometry and radiographic bone density assessments were made on the femora and tibiae. The lengths, masses and Seedor indices of the bones were similar $(p>0.05$, ANOVA) across the groups. Males that received curcumin with or without fructose during suckling and weaned onto a high-fructose diet had lower ( $p \leq 0.05$, ANOVA) osteocalcin concentration versus the other males. Similarly, in female rats, curcumin alone or administered with fructose resulted in lower ( $p \leq 0.05$, ANOVA) osteocalcin concentration versus female rats administered the vehicle control. Neonatal curcumin-induced decrease in plasma total osteocalcin concentration may predispose to adverse consequences on glucose metabolism and bone health.
\end{abstract}

Key words: Bone health - Metabolic syndrome - Childhood obesity - Plasma osteocalcin levels

\section{Introduction}

The prevalence of metabolic syndrome and its resultant deleterious effects are increasing globally (Falkner and Cossrow 2014). In children and adolescents, the metabolic syndrome epidemic is driven by a rising prevalence of childhood obesity (Ludwig 2018; Powell 2018). The increase in childhood obesity has been linked to an increase in the consumption of high fructose-containing foods and physical inactivity (Fulkerson 2018; Kral 2018). Childhood obesity is a multisystem

Electronic supplementary material. The online version of this article (doi: 10.4149/gpb_2019025) contains supplementary material.

Correspondence to: Kasimu Ghandi Ibrahim, Department of Physiology, Faculty of Basic Medical Sciences, College of Health Sciences, Usmanu Danfodiyo University, P.M.B. 2254, Sokoto, Nigeria E-mail: ghandi.kasimu@udusok.edu.ng disorder that results in severe complications in most systems of the body, including the skeletal system (Han et al. 2010).

The skeletal system provides the structural framework for the body and plays an essential role in the regulation of glucose metabolism in the body by virtue of being an essential insulin target tissue (Tangseefa et al. 2018). Bone metabolism or remodelling continually occurs throughout an individual's life and involves tightly regulated processes of formation of new bone tissue and resorption of old tissues (Sánchez-Duffhues et al. 2015). Osteoblasts originate from the bone marrow mesenchyme and undergo continuous differentiation over childhood/adolescence to become bone matrix tissues as well as having an adipogenic function (Ganguly et al. 2017).

Osteocalcin is a bone-derived hormone that is exclusively secreted by osteoblasts and then released into the general circulation (Kanazawa 2015). Osteocalcin undergoes carboxylation of three of its glutamyl residues which then en- 
hances its binding to hydroxyapatite in the bone matrix (Yeap et al. 2015). There is a second form of osteocalcin which is undercarboxylated. This undercarboxylated form of osteocalcin plays an active role in glucose metabolism by serving as a link between bone metabolism and glucose metabolism (Kanazawa 2015). Undercarboxylated osteocalcin facilitates insulin secretion directly by inducing the proliferation of the pancreatic $\beta$-cells and indirectly through its stimulation of the secretion of glucagon-like peptide 1 from the intestines (Tangseefa et al. 2018). Osteocalcin also stimulates the secretion of adiponectin from adipocytes, further enhancing insulin sensitivity in the body (Kanazawa 2015). Through a feedforward mechanism, both insulin and adiponectin stimulate the expression of osteocalcin in the osteoblasts as shown in Figure 1 (Kanazawa 2015). The osteoblasts have insulin receptors which control osteoblast development and subsequent secretion of osteocalcin (Fulzele et al. 2010). Therefore, a reduction in the blood osteocalcin concentration may disrupt the insulin signalling mechanism possibly leading to the development of insulin resistance (Saleem et al. 2010).

Though bone remodeling occurs throughout life (Sánchez-Duffhues et al. 2015), most of the bone mass increases in humans usually occur during adolescence and the peak bone mass is achieved during this developmental stage (Boot et al. 2010). Events that interfere with these bone mass increases result in suboptimal peak bone masses at adolescence and then subsequently increase the risks of developing bone diseases, including fractures in old age
(Rizzoli et al. 2010; Lee 2013). There is evidence that programming for long-term bone health occurs during the early critical periods of developmental plasticity, a phenomenon referred to as developmental programming (Devlin et al. 2013; Vickers 2014). This phenomenon whereby stressor events like nutritional perturbations in the critical periods of development alter gene expression and modify the individual's physiology, can influence the attainment of peak bone mass and therefore predispose to bone diseases in later life (Firth et al. 2017). The period of developmental plasticity extends from pre-conception to infancy (Firth et al. 2017) and during this critical window, epigenetic changes such as DNA methylation, histone modification and micro RNA production are usually induced or repressed by dietary and environmental factors (Park et al. 2017). Interventions in the suckling period in rats have been shown to either program or reprogram for metabolic health in later life. For example, neonatal administration of leptin in Wistar rats prevented the bone suppressive effects of maternal undernutrition in adult offspring (Firth et al. 2017).

The administration of a high-fructose diet to rats is an established model for inducing metabolic syndrome (Tappy and Mittendorfer 2012; Mamikutty et al. 2014). Because of the important role the skeletal system plays in metabolism, the metabolic changes induced by fructose may affect bone health (Bass et al. 2013). Interestingly, the effects of fructose on bone health have been rather conflicting with some studies reporting beneficial effects while others reported negative effects. For instance, feeding a high-fructose diet for 12 weeks

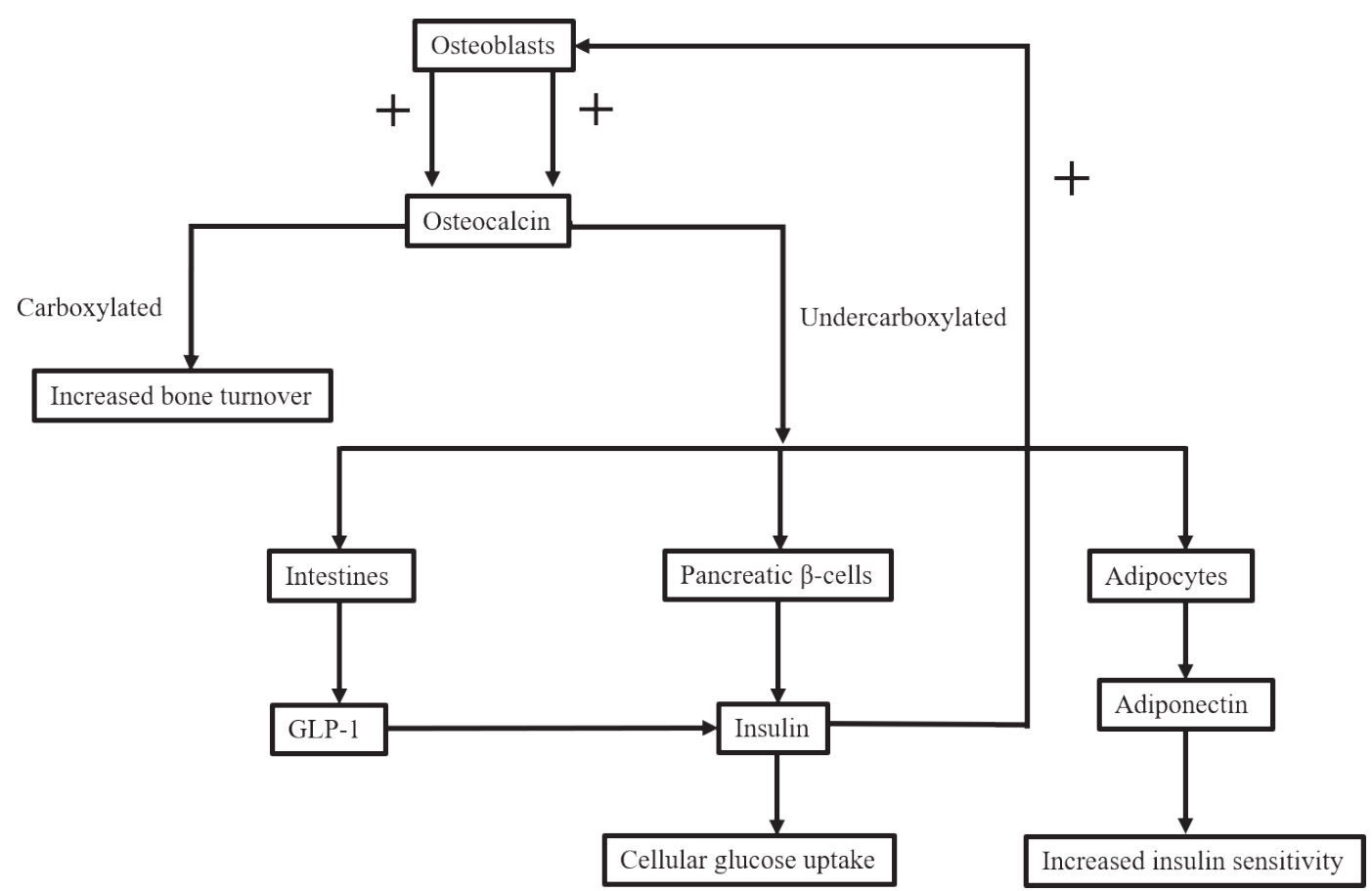

Figure 1. Schematic representation of the interactions between osteoblasts, pancreatic $\beta$ cells and adipocytes. GLP-1, glucagonlike peptide-1. 
was reported to lead to the formation of stronger bones with a better microarchitecture when compared to glucose in a rat model (Bass et al. 2013). Jatkar et al. (2017) also reported no negative effects on the bones of male BALB/cByJ (BALB) mice following 15 weeks of consuming a high-fructose diet. However, fructose has been shown to lead to the generation of reactive oxygen species in the body leading to oxidative stress that then causes an imbalance in the bone remodeling process by increasing bone resorption through stimulation of osteoclast activity (Yarrow et al. 2016).

Management of poor metabolic and bone health usually requires chronic or lifelong medications which in addition to poor patient compliance are also associated with side effects (Inamdar and Kulkarni 2017). Natural products such as plant polyphenols which are perceived to be safe and readily available are currently being extensively researched for their benefits in treating chronic conditions (Tsuda 2012; Bahmani et al. 2014). Some of these natural products have been used during suckling in rats as mentioned earlier, to program for long term protection against some metabolic diseases in later life (Lembede et al. 2018; Nyakudya et al. 2018).

Curcumin (diferuloylmethane) is a polyphenolic biologically active component of turmeric (Chainani-Wu 2003; Sahebkar 2013). Curcumin has demonstrated a wide array of biological activities in both in vitro and in vivo studies. Some of the documented biological activities of curcumin include: anti-obesity (Shao et al. 2012), anti-diabetic (Panahi et al. 2017), anti-oxidant (Ali et al. 2018) and anti-inflammatory (Elham et al. 2018). Additionally, curcumin has demonstrated beneficial effects in promoting good bone health by increasing bone strength and microarchitecture in ovariectomised postmenopausal rat model (Putnam et al. 2007; French et al. 2008).

Considering the previously established beneficial activity of curcumin against the components of metabolic syndrome and its ability to promote good bone health, we hypothesized that in rats, curcumin administration during suckling would program for improved bone health later in adolescence in the rats fed a high fructose diet post weaning. We show that there are no discernible changes to the bone health parameters, but the plasma total osteocalcin concentrations are decreased.

\section{Materials and Methods}

\section{Ethical clearance}

The study protocols were approved by the Animal Ethics Screening Committee of the University of the Witwatersrand, Johannesburg (AESC 2016/04/18/B). The study complied with international ethical guidelines and standards for the use of laboratory animals.

\section{Study location}

The study was conducted in the Central Animal Services (CAS) unit and the Endocrinology and Metabolism Laboratory, School of Physiology, Faculty of Health Sciences, University of the Witwatersrand, Johannesburg, Republic of South Africa.

\section{Study animals: housing and care}

One hundred and twenty-eight male and female Sprague Dawley pups which were six days old and delivered by fourteen dams sourced from the Central Animal Services Unit of the University of the Witwatersrand, Johannesburg were used in the study. The pups used were only those from dams with a litter size of between 8-12 pups to prevent litter size-effect on feeding. During the suckling phase, the pups nursed freely with their dams in perspex cages which were lined with wood shavings and shredded paper for environmental enrichment. The dams had ad libitum access to pelleted commercially sourced normal rat chow (Epol ${ }^{\oplus}$, Johannesburg, South Africa) and plain tap water to drink. The ambient temperature in the animal room was maintained at $26 \pm 2^{\circ} \mathrm{C}$ with adequate ventilation and a 12-hour light cycle (lights switched on at 7.00 am and off at $7.00 \mathrm{pm}$ ).

At weaning (postnatal day 21), the rat weanlings were placed in individual cages under similar environmental conditions as the pre-weaning stage. The dams were returned to stock.

\section{Chemicals and fructose}

For this study, dimethyl sulfoxide (DMSO; Sigma-Aldrich, Missouri, USA), curcumin (Sigma-Aldrich, Missouri, USA) and fructose (Nature's choice, Randvaal, South Africa) were used. The DMSO was used as the vehicle in which the other treatments were dissolved.

\section{Study design}

The study was carried out in two phases. The first phase of the study was conducted in the pre-weaning period; from post-natal day 6 to 21. The aim of the neonatal interventions was to induce programming of bone health. The second interventional phase extended from postnatal day 21 and continued for six weeks until postnatal day 63 (late adolescence) in order to determine whether the neonatal interventions had any effect on the response of the rats to a postweaning high fructose diet.

The pups $(n=128$ : males $=65$, females $=63)$ were allocatd in a split-litter pattern to four treatment groups replicated by sex in the first phase of the study. The treatment groups were as follows: 1. Control group: DMSO (0.5\%) in distilled water. (DMSO was the vehicle used to dissolve curcumin and fructose.) 
2. CC group: curcumin, $500 \mathrm{mg} / \mathrm{kg}$ body mass.

3. FW group: fructose $(20 \% \mathrm{w} / \mathrm{v})$.

4. CCFW group: curcumin $500 \mathrm{mg} / \mathrm{kg}+$ fructose $(20 \%, \mathrm{w} / \mathrm{v})$.

All the treatments were administered at $10 \mathrm{ml} / \mathrm{kg}$ body mass daily (between 8.30 a.m. and 10.00 a.m.) using an orogastric tube.

In the second phase of the study, the rats from each of the initial four groups were further sub-divided into two subgroups. While the two subgroups were weaned onto normal rat chow, one of the subgroups had plain tap water (PTW) and the other had fructose $(20 \%, \mathrm{w} / \mathrm{v} / \mathrm{FW})$ as their drinking fluid. The treatments in phase two were administered for six weeks until postnatal day 63. A schematic diagram of the study design is presented below (Figure 2).

\section{Body mass measurements}

The pups were weighed daily using a digital weighing scale (Snowrex Electronic Scale, Clover Scales, Johannesburg,
South Africa) during the first phase of the study to adjust their treatments to ensure constant dosing. In the second phase, the rats were weighed twice weekly to monitor their growth and general health. The dams were also weighed twice weekly as part of routine health monitoring and were returned to stock at weaning.

\section{Terminal procedures}

On postnatal day 63, the body masses of the rats were determined using a weighing scale (Snowrex Electronic Scale, Clover Scales, Johannesburg, South Africa). The rats were subsequently terminated by anaesthetic overdose using intraperitoneal sodium pentobarbitone $(150 \mathrm{mg} / \mathrm{kg}$ body mass, Euthapent; Kyron laboratories, South Africa). Blood was taken via cardiac puncture and transferred into heparinised blood collecting tubes (Becton Dickinson Vacutainer Systems Europe, Meylan Cedex, France). The blood was subsequently processed in a centrifuge (Hermle Z 230A, B Hermle AG,

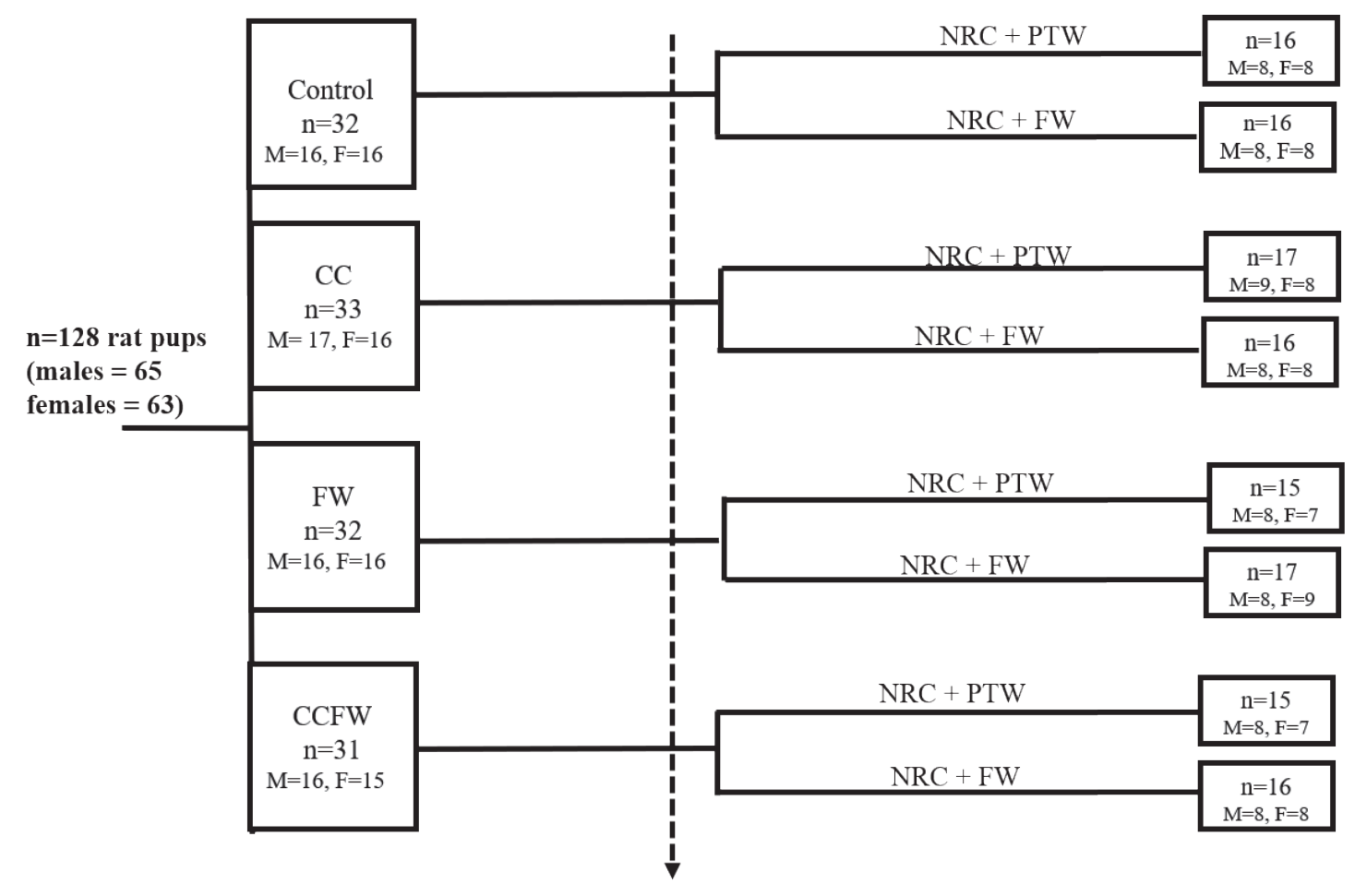

P1 ${ }_{\text {Adaptation }}^{\text {Adarst interventional phase }}$ P21 $\quad$ Second interventional phase

Figure 2. Schematic diagram of the study design. Newly born pups were obtained as described in the Materials and Methods. The study was carried out in two phases. The first phase of the study was conducted in the pre-weaning period; from postnatal day 6 to 21 . Rats were assigned to four treatment groups: Control (treated with DMSO), CC (treated with curcumin ( $500 \mathrm{mg} / \mathrm{kg}$ body mass)). FW (treated with fructose $(20 \% \mathrm{w} / \mathrm{v})$ ) and CCFW (combination of CC and FW). The second interventional phase extended from postnatal day 21 and continued for six weeks until postnatal day 63. Rats from each of the four groups were further sub-divided into two subgroups: NRC+PTW (normal rat chow + plain tap water) and NRC+FW (normal rat chow + fructose $(20 \%, \mathrm{w} / \mathrm{v} /$ )). M, males; F, females; P, postnatal day. 
Germany) at $4000 \times g$ at $4^{\circ} \mathrm{C}$ for 15 minutes and the plasma was collected and stored in microtubes (Eppendorf, Hamburg, Germany) at $-80^{\circ} \mathrm{C}$ (ESCO, Lexicon ${ }^{\circledR}$ ULT Freezer, Hatboro, PA, USA) for osteocalcin assay. The carcasses of the rats were stored in a freezer until dissection of the long bones.

\section{Determination of bone morphometric parameters}

The carcasses were removed from the freezer and allowed to thaw overnight at $4^{\circ} \mathrm{C}$. The left hind limbs were carefully detached from the acetabulum and the femora and tibiae were defleshed with a scalpel and scissors. The two bones were disarticulated from each other and dried in an oven (Salvis) at $50^{\circ} \mathrm{C}$ for 5 days till constant masses were achieved. The masses of the bones were determined using an electronic weighing scale (Precisa $310 \mathrm{M}$, Instrulab, Johannesburg, South Africa). The lengths of the bones were then determined using a digital Vernier caliper (Major Tech (Pty) Ltd., KTV 150 digital caliper, Elandsfontein, South Africa).

The relative densities of the bones were computed using the Seedor index (Seedor et al. 1991) as follows: Seedor index $=$ mass/length $(\mathrm{mg} / \mathrm{mm})$. The higher the Seedor index, the greater the density of the bone (Monteagudo et al. 1997).

\section{Radiographic assessment of the relative bone densities}

Radiographs of representative samples of tibiae and femora from each treatment group were taken using a Shimadzu Mux 200 X-ray machine (Shimadzu Corporation, Kyoto, Japan). The bones were placed on a Fujifilm FCR $24 \times 30 \mathrm{~cm}$ IP Cassette type CC at a $100 \mathrm{~cm}$ distance from the radiation light source. Settings of 2.8 MAS and $58 \mathrm{kV}$ were used for exposure. The radiographs were digitised using a Fujifilm FCR PRIMA and viewed using MeDiViewer (version 1.3.2, JDK 1.3.1_08, Schaf Systemtechnik GmbH, Falkenstrabe 22, 91580 Petersaurach).

\section{Determination of plasma osteocalcin concentration}

Total plasma osteocalcin concentration was determined using a commercial rat-specific sandwich enzyme-linked immunosorbent assay kit (Elabscience ${ }^{\oplus}$, Rat OC/BGP (Osteocalcin) ELISA kit, Houston, TX, USA). The ELISA protocol was followed according to the manufacturer's instructions. The plasma osteocalcin concentrations (ng/ $\mathrm{ml}$ ) were extrapolated from standard curve generated using known osteocalcin concentrations.

\section{Statistical analysis}

Data was analysed using GraphPad Prism version 7.0 statistical software (GraphPad Software Inc., San Diego, CA, USA) and expressed as mean \pm standard error of mean (SEM). Data was
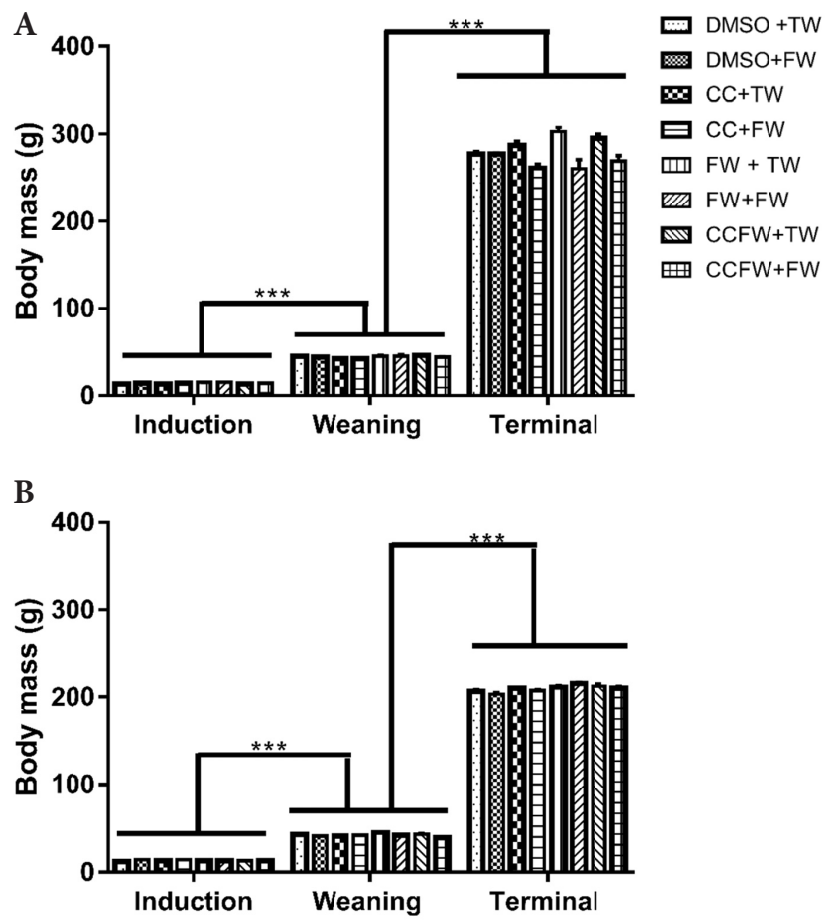

Figures 3. Effect of a high-fructose diet on body mass changes of (A) male and (B) female Sprague Dawley rats that were administered curcumin orally during suckling. Data expressed as mean \pm SEM; ${ }^{* * *} p<0.0001 ; n=6-8$ per group. For abbreviations, see Fig. 2.

analysed using a one-way analysis of variance (ANOVA), followed by a comparison of the means using the Bonferroni post hoc test. Statistical significance was assumed when $p \leq 0.05$.

\section{Results}

\section{Body mass changes}

The body mass changes at induction, weaning and termination of male and female Sprague Dawley rats that were administered with oral curcumin during suckling are presented in Figure 3. There were no differences ( $p>0.05$, ANOVA) in the mean body masses across the treatment groups at each of the three time points in both male and female rats. However, both male and female rats gained significant $(p<$ 0.0001 , ANOVA) body mass from induction through weaning and termination.

\section{Indices of femora and tibiae health}

Table 1 shows the effect of the interventions on the lengths, masses and Seedor indices of femora and tibiae of male and female rats, respectively. There were no differences $(p>0.05$, ANOVA) across the treatment groups in the lengths, masses 
and Seedor indices of the femora and tibiae of the male and female rats. The representative radiographic images of the femora and tibiae of male and female Sprague Dawley rats that were administered with curcumin during suckling and subsequently fed a high-fructose diet post weaning are presented as Figure 4. There were no discernible differences in the density of both the femora and tibiae of male and female rats across the treatment groups.

\section{Plasma osteocalcin concentration changes}

The effect of a high-fructose diet on the plasma concentration of osteocalcin in male and female Sprague Dawley rats that were orally administered with curcumin during suckling are presented in Figure 5. Male rats that were administered with curcumin alone and those administered with a combination of curcumin and fructose during suckling and subsequently fed a high-fructose diet had significantly lower $(p \leq 0.05$, ANOVA) total plasma osteocalcin concentration compared to that of rats from other treatment groups. In the female rats, administration of curcumin alone or combined curcumin and fructose during suckling and then subsequent feeding with a high-fructose diet post weaning resulted in significantly lower ( $p \leq 0.05$, ANOVA) total plasma osteocalcin concentration compared to administration of DMSO during suckling and then feeding with a high-fructose diet post weaning.

\section{Discussion}

The major finding in this study was that administration of curcumin alone or in combination with fructose during suckling resulted in a reduced total plasma concentration of osteocalcin following a postweaning high-fructose diet in both male and female rats. The total plasma osteocalcin comprises of the carboxylated and undercarboxylated forms of osteocalcin, thus, the findings could be interpreted in two different ways. Whereas, a low concentration of carboxylated osteocalcin implies a low bone turnover, reduced bone loss and good bone health; a low concentration of undercarboxylated osteocalcin may imply an impairment of glucose metabolism probably because of the postweaning high fructose diet. It is important to mention here that both the fasting blood glucose and plasma insulin concentration were similar across treatment groups in both male and female rats (data not shown but presented in Supplemental Tables S1 and S2).

A high-fructose diet is known to induce features of metabolic syndrome including hyperglycaemia and insulin resistance (Stanhope and Havel 2010; Tappy and Mittendorfer 2012). The low levels of osteocalcin that were noted only in the high fructose groups that had previously been administered with curcumin during suckling may imply that curcumin predisposed the rats to the adverse effects of the post weaning high fructose diet. Osteocalcin is an important non-collagenous protein biochemical marker of bone turno-

Table 1. Effect of a high-fructose diet on the lengths, masses and Seedor index of the bones of male and female Sprague Dawley rats fed curcumin during suckling

\begin{tabular}{|c|c|c|c|c|c|c|}
\hline \multirow[b]{2}{*}{ Group } & \multicolumn{3}{|c|}{ Femur } & \multicolumn{3}{|c|}{ Tibia } \\
\hline & $\begin{array}{l}\text { Length } \\
(\mathrm{mm})\end{array}$ & $\begin{array}{l}\text { Mass } \\
(\mathrm{mg})\end{array}$ & $\begin{array}{c}\text { Seedor index } \\
(\mathrm{mg} / \mathrm{mm})\end{array}$ & $\begin{array}{l}\text { Length } \\
(\mathrm{mm})\end{array}$ & $\begin{array}{l}\text { Mass } \\
(\mathrm{mg})\end{array}$ & $\begin{array}{c}\text { Seedor index } \\
(\mathrm{mg} / \mathrm{mm})\end{array}$ \\
\hline \multicolumn{7}{|l|}{ Male } \\
\hline $\mathrm{DMSO}+\mathrm{PTW}$ & $32 \pm 0.46$ & $479 \pm 16$ & $15 \pm 0.32$ & $36 \pm 0.53$ & $400 \pm 13$ & $11 \pm 0.23$ \\
\hline $\mathrm{DMSO}+\mathrm{FW}$ & $32 \pm 0.44$ & $484 \pm 11$ & $15 \pm 0.17$ & $36 \pm 0.29$ & $378 \pm 14$ & $10 \pm 0.33$ \\
\hline $\mathrm{CC}+\mathrm{PTW}$ & $33 \pm 0.61$ & $488 \pm 21$ & $15 \pm 0.38$ & $37 \pm 0.53$ & $414 \pm 14$ & $11 \pm 0.26$ \\
\hline $\mathrm{CC}+\mathrm{FW}$ & $32 \pm 1.20$ & $442 \pm 32$ & $14 \pm 0.69$ & $36 \pm 0.51$ & $364 \pm 29$ & $10 \pm 0.73$ \\
\hline $\mathrm{FW}+\mathrm{PTW}$ & $33 \pm 1.10$ & $526 \pm 29$ & $16 \pm 0.37$ & $37 \pm 0.57$ & $441 \pm 15$ & $12 \pm 0.33$ \\
\hline $\mathrm{FW}+\mathrm{FW}$ & $31 \pm 0.43$ & $468 \pm 14$ & $15 \pm 0.28$ & $36 \pm 0.41$ & $386 \pm 12$ & $11 \pm 0.29$ \\
\hline CCFW+PTW & $33 \pm 0.93$ & $508 \pm 21$ & $15 \pm 0.45$ & $37 \pm 0.56$ & $424 \pm 14$ & $11 \pm 0.23$ \\
\hline $\mathrm{CCFW}+\mathrm{FW}$ & $31 \pm 0.70$ & $468 \pm 30$ & $16 \pm 1.10$ & $36 \pm 0.87$ & $394 \pm 19$ & $11 \pm 0.39$ \\
\hline \multicolumn{7}{|l|}{ Female } \\
\hline $\mathrm{DMSO}+\mathrm{PTW}$ & $30 \pm 0.42$ & $432 \pm 16$ & $14 \pm 0.35$ & $35 \pm 0.33$ & $354 \pm 11$ & $10 \pm 0.23$ \\
\hline $\mathrm{DMSO}+\mathrm{FW}$ & $30 \pm 0.30$ & $414 \pm 17$ & $14 \pm 0.43$ & $35 \pm 0.27$ & $335 \pm 14$ & $9.7 \pm 0.34$ \\
\hline $\mathrm{CC}+\mathrm{PTW}$ & $32 \pm 0.93$ & $438 \pm 11$ & $14 \pm 0.39$ & $35 \pm 0.27$ & $358 \pm 9.6$ & $10 \pm 0.20$ \\
\hline $\mathrm{CC}+\mathrm{FW}$ & $30 \pm 0.16$ & $431 \pm 9.5$ & $14 \pm 0.28$ & $35 \pm 0.21$ & $354 \pm 4.2$ & $10 \pm 0.08$ \\
\hline FW+PTW & $30 \pm 0.15$ & $457 \pm 6.2$ & $15 \pm 0.15$ & $36 \pm 0.91$ & $368 \pm 6$ & $10 \pm 0.31$ \\
\hline $\mathrm{FW}+\mathrm{FW}$ & $31 \pm 0.53$ & $449 \pm 14$ & $15 \pm 0.46$ & $35 \pm 0.17$ & $370 \pm 5.5$ & $11 \pm 0.12$ \\
\hline $\mathrm{CCFW}+\mathrm{PTW}$ & $31 \pm 0.32$ & $463 \pm 15$ & $15 \pm 0.34$ & $37 \pm 1.3$ & $369 \pm 8.1$ & $10 \pm 0.23$ \\
\hline $\mathrm{CCFW}+\mathrm{FW}$ & $30 \pm 0.56$ & $433 \pm 28$ & $14 \pm 0.66$ & $35 \pm 0.51$ & $343 \pm 15$ & $9.9 \pm 0.34$ \\
\hline
\end{tabular}



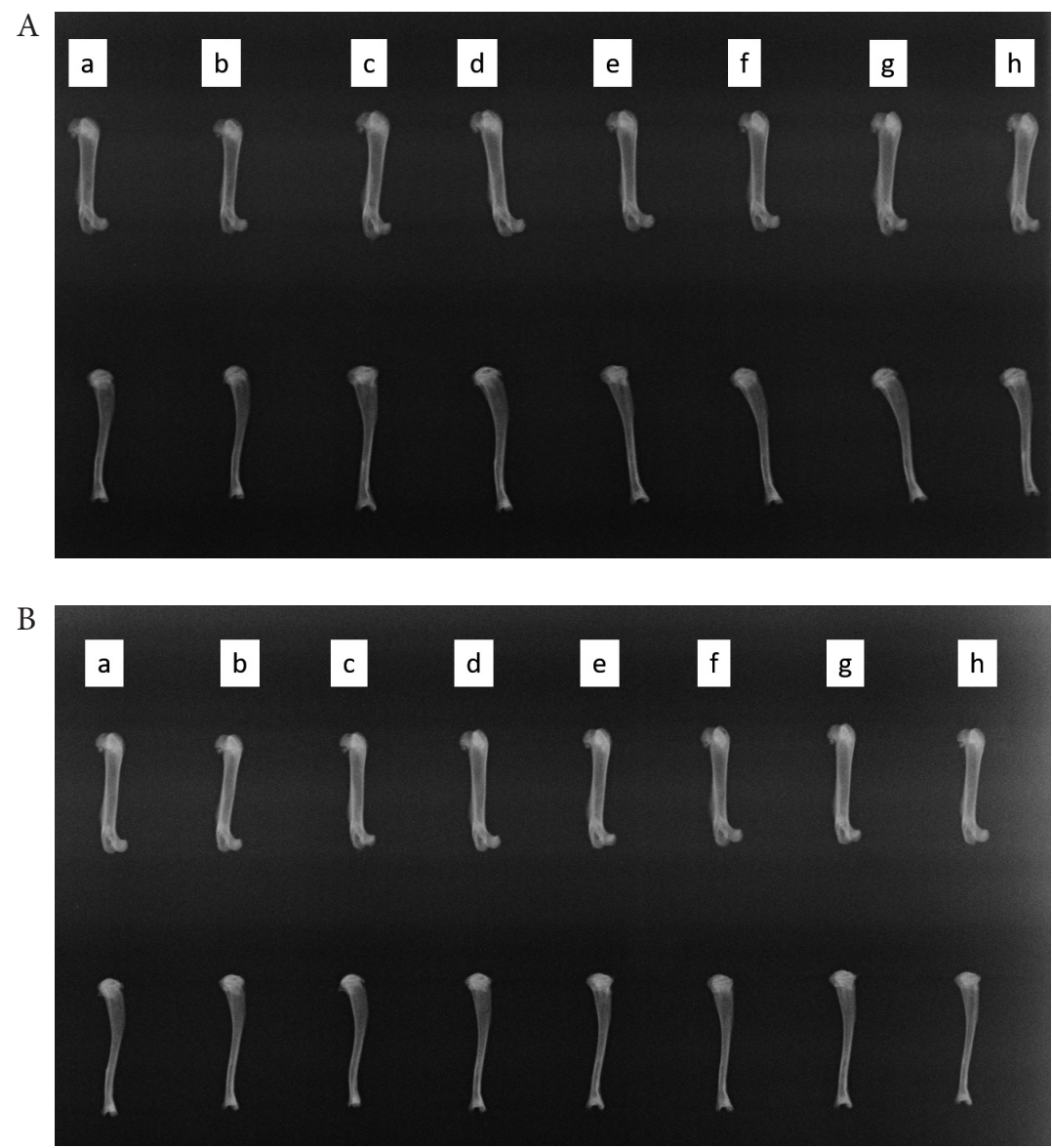

Figures 4. Representative radiographs showing the effect of a high-fructose diet on the of the femora (top) and tibiae (bottom) of adolescent (A) male and (B) female Sprague Dawley rats that were administered curcumin during suckling. Groups: DMSO+PTW (a), DMSO+FW (b), CC+PTW (c), CC+FW (d), FW+PTW (e), $\mathrm{FW}+\mathrm{FW}(\mathbf{f}), \mathrm{CCFW}+\mathrm{PTW}(\mathbf{g}), \mathrm{CCFW}+\mathrm{FW}$ (h). Representative images of $n=6-8$ per group are shown. For abbreviations, see Fig. 2.

ver that is found in abundance in the bone matrix (Nikel et al. 2018). Most of the osteocalcin exists in the carboxylated form and is involved in bone remodeling (Namai et al. 2018). Undercarboxylated osteocalcin is involved in glucose metabolism regulation and its deficiency leads to the development of insulin resistance (Saleem et al. 2010; Namai et al. 2018). Previous studies on the effects of neonatal administration of fructose in rats focused on its programming effects on metabolism (Huynh et al. 2008; Ghezzi et al. 2012) and not on long-term bone health. However, it has been previously shown that a $25 \%$ fructose (w/v) administered to 12 -week old male Wistar rats did not induce any significant changes in the plasma osteocalcin concentration (Dai et al. 2017). It is therefore not surprising that we did not observe significant effects in the groups that had only fructose without curcumin when compared to the control in both sexes.

Contrary to our findings, curcumin was found to induce osteoblast differentiation by increasing the expression of genes that induce osteoblast differentiation, such as runtrelated transcription factor 2 (Runx2) and osteocalcin in an in vitro study (Son et al. 2018). The beneficial effects of curcumin on bone health were further shown in another study involving spinal cord injury subjects with low bone density where it prevented further bone loss and improved the bone density (Hatefi et al. 2018). It is possible that curcumin only lowers osteocalcin levels when a high fructose diet disrupts the positive feedback loop that exists between osteocalcin and insulin concentrations (Kanazawa 2015). Therefore, the pre-weaning administration of curcumin may have epigenetically programmed the rats for lower osteocalcin concentration later in life.

We did not find any differences in the bone lengths, masses and Seedor indices in both male and female rats. This further suggests that it is probably the endocrine functions of the bones that were affected by our interventions and not the bone density. Though postweaning feeding with fructose has been reported in several studies not to exert any effect on the morphometry of the femora and tibiae of rats (Ibrahim et al. 2017; Lembede et al. 2018); Douard et al. (2013) had previously reported shorter femora in male Sprague Dawley rats that were fed a $63 \%$ fructose diet for 4 weeks when compared to control rats due to decreased calcium absorption and vitamin $\mathrm{D}$ deficiency caused by the high fructose diet. Fructose metabolism in the body has been associated with generation of reactive oxygen species leading to oxidative stress (Yarrow et al. 2016). This oxidative stress 

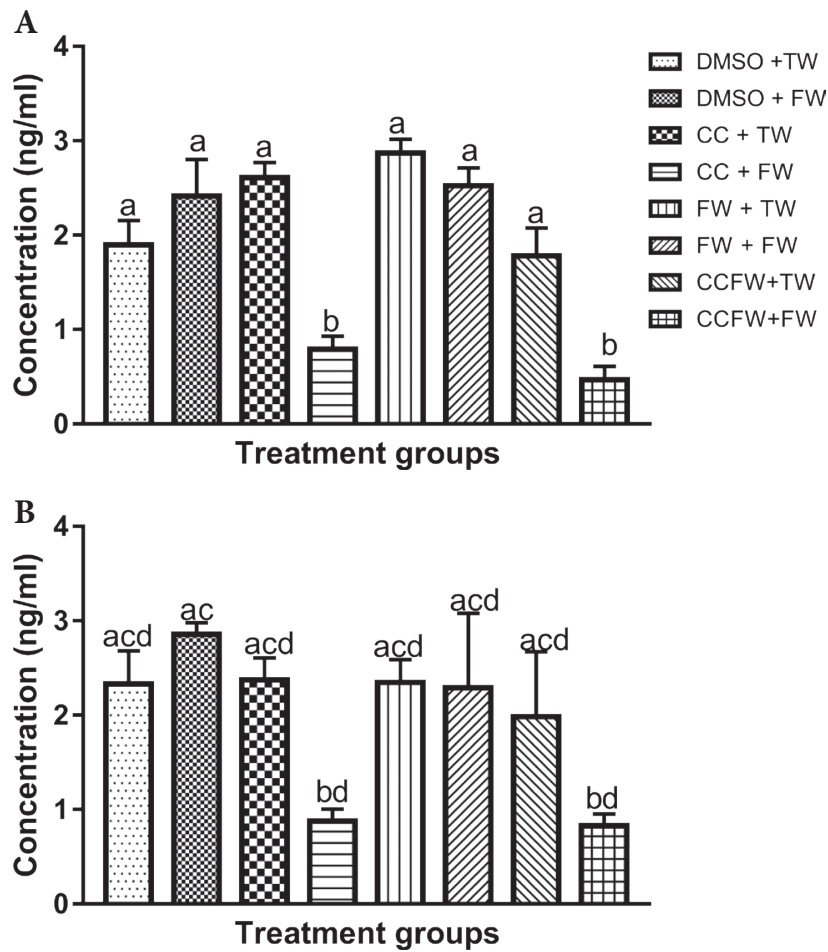

Figures 5. Effect of a high-fructose diet on the plasma concentration of total osteocalcin of (A) male and (B) female Sprague Dawley rats that were administered curcumin during suckling. ${ }^{\text {a, b, c, d }}$ significantly different from each other at $p \leq 0.05$. Data expressed as mean \pm SEM, $n=6-8$ per group. For abbreviations, see Fig. 2.

induces osteoblast apoptosis which inhibits bone growth (Dai et al. 2017). In our present study, we did not observe any obvious inhibition of bone growth as a result of either the administration of curcumin or the high-fructose diet.

We did not observe any differences in the body masses of both male and female rats across the treatment groups even though all the animals gained significant body mass through the stages of the study. This suggests that both the neonatal and postweaning interventions did not have any adverse effect on the growth of the rats. Although high fructose administration has been shown to induce changes in body mass due to increased adiposity (Bocarsly et al. 2010; Mamikutty et al. 2014), younger rats were shown to be resistant to this body mass change due to their rapid growth and higher metabolic rate (Tillman et al. 2014) into which they channel the consumed calories rather than into deposition of adipose tissue. Body mass changes due to fructose administration were found to become obvious only after postnatal day 100 in rats (Patel and Srinivasan 2010). The rats in this study were terminated on postnatal day 63 and therefore this might explain the similarity in their body masses.

Though the use of Seedor index to estimate bone density is acceptable (Monteagudo et al. 1997), measuring bone mineral content and bone mineral density of bones with dual-energy x-ray absorptiometry (DXA) (VanGompel et al. 2017) would have been preferable. Bone breaking strength tests would have given more information on the density of the bones. We measured total osteocalcin concentration and not the different forms which may provide different results and suggest an alternative mechanism.

\section{Conclusion}

Oral administration of curcumin alone or with fructose during suckling reduced total plasma osteocalcin concentration following a postweaning high fructose diet. These findings suggest that while administration of curcumin during periods of developmental plasticity may worsen the disruption of glucose homeostasis induced by a high fructose diet, it probably reduces bone turnover. Thus, despite the potential role for curcumin in the prevention of fructose induced bone diseases, it should be used with caution in the neonatal age groups.

Acknowledgement. The authors acknowledge the technical support received from Ms Monica Gomes and staff of the Central Animal Services of the University of the Witwatersrand, Johannesburg. This study was funded by the Faculty of Health Sciences, University of the Witwatersrand medical research endowment fund (KGI, Grant number: 001.251.8521101.5121105.000000. $0000000000.4550)$ and the National Research Foundation of South Africa (KHE, Grant number: IRF 2010041900009).

Conflict of interest. The authors declare no conflict of interest.

Author contributions. KGI, EC and KHE contributed to the design of the work, the interpretation of the data and the revision of the manuscript. KGI, HLW and MTM contributed to the acquisition and interpretation of the data, and the drafting of the manuscript. All authors agree to be accountable for the entire content of the manuscript and approved the final version of the manuscript. All persons who qualify for authorship are listed as authors.

\section{References}

Ali BH, Suhail AS, Yousuf AS, Jamila AK, Shadia AB, Mohammed A, Priyadarsini M, Buthaina AD, Nadia AA, Heba NT, et al. (2018): Curcumin ameliorates kidney function and oxidative stress in experimental chronic kidney disease. Basic Clin. Pharmacol. Toxicol. 122, 65-73 https://doi.org/10.1111/bcpt.12817

Bahmani M, Zargaran A, Rafieian-Kopaei M, Saki K (2014): Ethnobotanical study of medicinal plants used in the management of diabetes mellitus in the Urmia, Northwest Iran. Asian Pac. J. Trop. Biomed. 7, S348-S354 https://doi.org/10.1016/S1995-7645(14)60257-1 
Bass EF, Baile CA, Lewis RD, Giraudo SQ (2013): Bone quality and strength are greater in growing male rats fed fructose compared with glucose. Nutr. Res. 33, 1063-1071

https://doi.org/10.1016/j.nutres.2013.08.006

Bocarsly ME, Powell ES, Avena NM, Hoebel BG (2010): Highfructose corn syrup causes characteristics of obesity in rats: increased body weight, body fat and triglyceride levels. Pharmacol. Biochem. Behav. 97, 101-106 https://doi.org/10.1016/j.pbb.2010.02.012

Boot AM, De Ridder MA, Van Der Sluis IM, Van Slobbe I, Krenning EP, De Muinck Keizer-Schrama SM (2010): Peak bone mineral density, lean body mass and fractures. Bone 46, 336-341 https://doi.org/10.1016/j.bone.2009.10.003

Chainani-Wu N (2003) Safety and anti-inflammatory activity of curcumin: a component of tumeric (Curcuma longa). J. Altern. Complement. Med. 9, 161-168 https://doi.org/10.1089/107555303321223035

Dai P, Mao Y, Sun X, Li X, Muhammad I, Gu W, Zhang D, Zhou Y, Ni Z, Ma J (2017): Attenuation of oxidative stress-induced osteoblast apoptosis by curcumin is associated with preservation of mitochondrial functions and increased Akt-GSK3 $\beta$ signaling. Cell. Physiol. Biochem. 41, 661-677 https://doi.org/10.1159/000457945

Devlin M, Grasemann C, Cloutie A, Louis L, Alm C, Palmert M, Bouxsein M (2013): Maternal perinatal diet induces developmental programming of bone architecture. J. Endocrinol. 217, 69-81 https://doi.org/10.1530/JOE-12-0403

Douard V, Sabbagh Y, Lee J, Patel C, Kemp FW, Bogden JD, Lin S, Ferraris RP (2013): Excessive fructose intake causes 1,25-(OH) (2)D(3)-dependent inhibition of intestinal and renal calcium transport in growing rats. Am. J. Physiol. Endocrinol. Metab. 304, E1303-E1313 https://doi.org/10.1152/ajpendo.00582.2012

Elham A, Abbas MA, Thomas J, Amirhossein S (2018): Therapeutic effects of curcumin in inflammatory and immune-mediated diseases: A nature-made jack-of-all-trades? J. Cell. Physiol. 233, 830-848 https://doi.org/10.1002/jcp.25778

Falkner B, Cossrow ND (2014): Prevalence of metabolic syndrome and obesity-associated hypertension in the racial ethnic minorities of the United States. Curr. Hypertens. Rep. 16, 1-8 https://doi.org/10.1007/s11906-014-0449-5

Firth EC, Gamble GD, Cornish J, Vickers MH (2017): Neonatal leptin treatment reverses the bone-suppressive effects of maternal undernutrition in adult rat offspring. Sci. Rep. 7, 7686 https://doi.org/10.1038/s41598-017-07500-5

French DL, Muir JM, Webber CE (2008): The ovariectomized, mature rat model of postmenopausal osteoporosis: An assessment of the bone sparing effects of curcumin. Phytomed. 15, 1069-1078 https://doi.org/10.1016/j.phymed.2008.06.007

Fulkerson JA (2018): Fast food in the diet: Implications and solutions for families. Physiol. Behav. 193, 252-256 https://doi.org/10.1016/j.physbeh.2018.04.005

Fulzele K, Riddle RC, Digirolamo DJ, Cao X, Wan C, Chen D, Faugere M.-C, Aja S, Hussain MA, Brüning JC (2010): Insulin receptor signaling in osteoblasts regulates postnatal bone acquisition and body composition. Cell 142, 309-319 https://doi.org/10.1016/j.cell.2010.06.002

Ganguly P, El-Jawhari JJ, Giannoudis PV, Burska AN, Ponchel F, Jone EA (2017): Age-related changes in bone marrow mesenchymal stromal cells: a potential impact on osteoporosis and osteoarthritis development. Cell Transplant. 26, 1520-1529 https://doi.org/10.1177/0963689717721201

Ghezzi AC, Cambri LT, Botezelli JD, Ribeiro C, Dalia RA, Rostom De Mello, MA (2012): Metabolic syndrome markers in wistar rats of different ages. Diabetol. Metab. Syndr. 4, 16 https://doi.org/10.1186/1758-5996-4-16

Han JC, Lawlor DA, Kimm SYS (2010): Childhood obesity. The Lancet 375, 1737-1748 https://doi.org/10.1016/S0140-6736(10)60171-7

Hatefi M, Ahmadi MRH, Rahmani A, Dastjerd MM, Asadollahi K (2018): Effects of curcumin on bone loss and biochemical markers of bone turnover in patients with spinal cord injury. World Neurosurg. 114, e785-e791 https://doi.org/10.1016/j.wneu.2018.03.081

Huynh M, Luiken JJ, Coumans W, Bell RC (2008): Dietary fructose during the suckling period increases body weight and fatty acid uptake into skeletal muscle in adult rats. Obesity 16, 1755-1762 https://doi.org/10.1038/oby.2008.268

Ibrahim KG, Chivandi E, Mojiminiyi FBO, Erlwanger KH (2017): The response of male and female rats to a high-fructose diet during adolescence following early administration of Hibiscus sabdariffa aqueous calyx extracts. J. Dev. Orig. Health Dis. 8, 628-637 https://doi.org/10.1017/S204017441700040X

Inamdar SZ, Kulkarni RV (2017): Anti-diabetics drug usage and related pharmaceutical care issues among geriatrics and non-geriatrics: A comparative assessment. Indian J. Pharm. Pract. 10, 161 https://doi.org/10.5530/ijopp.10.3.35

Jatkar A, Kurland IJ, Judex S (2017): Diets high in fat or fructose differentially modulate bone health and lipid metabolism. Calcified Tissue Int. 100, 20-28 https://doi.org/10.1007/s00223-016-0205-8

Kanazawa I (2015): Osteocalcin as a hormone regulating glucose metabolism. World J. Diabetes 6, 1345-1354 https://doi.org/10.4239/wjd.v6.i18.1345

Kral TVE (2018): Behavioral phenotypes for childhood obesity: 2017 Alan N. Epstein Research Award. Physiol. Behav. 192, 206-209 https://doi.org/10.1016/j.physbeh.2018.01.003

Lee K (2013): Sex-specific relationships between insulin resistance and bone mineral content in Korean adolescents. J. Bone Miner. Metab. 31, 177-182 https://doi.org/10.1007/s00774-012-0396-7

Lembede BW, Erlwanger K, Nkomozepi P, Chivandi E (2018): Effect of neonatal orally administered S-allyl cysteine in high-fructose diet fed Wistar rats. J. Dev. Orig. Health Dis. 9, 160-171 https://doi.org/10.1017/S2040174417000940

Ludwig DS (2018) Epidemic childhood obesity: Not yet the end of the beginning. Pediatrics e20174078 https://doi.org/10.1542/peds.2017-4078

Mamikutty N, Thent ZC, Sapri SR, Sahruddin NN, Mohd Yusof MR, Haji Suhaimi F (2014): The establishment of metabolic syndrome model by induction of fructose drinking water in male Wistar rats. BioMed. Res. Int. 2014, 1-8 https://doi.org/10.1155/2014/263897 
Monteagudo M, Hernandez E, Seco C, Gonzalez-Riola J, Revilla M, Villa L, Rico H (1997): Comparison of the bone robusticity index and bone weight/bone length index with the results of bone densitometry and bone histomorphometry in experimental studies. Cells Tissues Organs 160, 195-199 https://doi.org/10.1159/000148011

Namai F, Shigemori S, Sudo K, Sato T, Yamamoto Y, Nigar S, Ogita T, Shimosato T (2018): Recombinant mouse osteocalcin secreted by Lactococcus lactis promotes glucagon-like peptide- 1 induction in STC-1 cells. Curr. Microbiol. 75, 92-98 https://doi.org/10.1007/s00284-017-1354-3

Nikel O, Poundarik AA, Bailey S, Vashishth D (2018): Structural role of osteocalcin and osteopontin in energy dissipation in bone. J. Biomech. 80, 45-52 https://doi.org/10.1016/j.jbiomech.2018.08.014

Nyakudya T, Mukwevho E, Nkomozepi P, Erlwanger K (2018): Neonatal intake of oleanolic acid attenuates the subsequent development of high fructose diet-induced non-alcoholic fatty liver disease in rats. J. Dev. Orig. Health Dis. 9, 500-510 https://doi.org/10.1017/S2040174418000259

Panahi Y, Khalili N, Sahebi E, Namazi S, Karimian MS, Majeed M, Sahebkar A (2017): Antioxidant effects of curcuminoids in patients with type 2 diabetes mellitus: a randomized controlled trial. Inflammopharmacology 25, 25-31 https://doi.org/10.1007/s10787-016-0301-4

Park J-H, Kim S-H, Lee MS, Kim M-S (2017): Epigenetic modification by dietary factors: Implications in metabolic syndrome. Mol. Aspects Med. 54, 58-70 https://doi.org/10.1016/j.mam.2017.01.008

Patel MS, Srinivasan M (2010): Metabolic programming due to alterations in nutrition in the immediate postnatal period. J. Nutr. 140, 658-661 https://doi.org/10.3945/jn.109.110155

Powell D (2018): Governing the (un) healthy child-consumer in the age of the childhood obesity crisis. Sport Educ. Soc. 23, 297-310 https://doi.org/10.1080/13573322.2016.1192530

Putnam SE, Scutt AM, Bicknell K, Priestley CM, Williamson EM (2007): Natural products as alternative treatments for metabolic bone disorders and for maintenance of bone health. Phytother. Res. 21, 99-112 https://doi.org/10.1002/ptr.2030

Rizzoli R, Bianchi ML, Garabédian M, Mckay HA, Moreno LA (2010): Maximizing bone mineral mass gain during growth for the prevention of fractures in the adolescents and the elderly. Bone 46, 294-305 https://doi.org/10.1016/j.bone.2009.10.005

Sahebkar A (2013): Why it is necessary to translate curcumin into clinical practice for the prevention and treatment of metabolic syndrome? Biofactors 39, 197-208 https://doi.org/10.1002/biof.1062

Saleem U, Mosley Jr TH, Kullo IJ (2010): Serum osteocalcin is associated with measures of insulin resistance, adipokine levels, and the presence of metabolic syndrome. Arterioscler. Thromb. Vasc. Biol. 30, 1474-1478 https://doi.org/10.1161/ATVBAHA.110.204859

Sánchez-Duffhues G, Hiepen C, Knaus P, Ten Dijke P (2015): Bone morphogenetic protein signaling in bone homeostasis. Bone 80, 43-59 https://doi.org/10.1016/j.bone.2015.05.025

Seedor JG, Quartuccio HA, Thompson DD (1991): The bisphosphonate alendronate (MK-217) inhibits bone loss due to ovariectomy in rats. J. Bone Miner. Res. 6, 339-346 https://doi.org/10.1002/jbmr.5650060405

Shao W, Yu Z, Chiang Y, Yang Y, Chai T, Foltz W, Lu H, Fantus IG, Jin T (2012): Curcumin prevents high fat diet induced insulin resistance and obesity via attenuating lipogenesis in liver and inflammatory pathway in adipocytes. PloS One 7, e28784 https://doi.org/10.1371/journal.pone.0028784

Son H-E Kim E-J Jang W-G (2018): Curcumin induces osteoblast differentiation through mild-endoplasmic reticulum stressmediated such as BMP2 on osteoblast cells. Life Sci. 193, 34-39 https://doi.org/10.1016/j.lfs.2017.12.008

Stanhope KL, Havel PJ (2010): Fructose consumption: recent results and their potential implications. Ann. NY Acad. Sci. 1190, 15-24 https://doi.org/10.1111/j.1749-6632.2009.05266.x

Tangseefa P, Martin SK, Fitter S, Baldock PA, Proud G, Zannettino AC (2018): Osteocalcin-dependent regulation of glucose metabolism and fertility: Skeletal implications for the development of insulin resistance. J. Cell. Physiol. 233, 3769-3783 https://doi.org/10.1002/jcp.26163

Tappy L, Mittendorfer B (2012): Fructose toxicity: is the science ready for public health actions? Curr. Opin. Clin. Nutr. Metab. Care 15, 357-361 https://doi.org/10.1097/MCO.0b013e328354727e

Tillman EJ, Morgan DA, Rahmouni K, Swoap SJ (2014): Three months of high-fructose feeding fails to induce excessive weight gain or leptin resistance in mice. PloS One 9, e107206 https://doi.org/10.1371/journal.pone.0107206

Tsuda T (2012): Dietary anthocyanin-rich plants: biochemical basis and recent progress in health benefits studies. Mol. Nutr. Food Res. 56, 159-170 https://doi.org/10.1002/mnfr.201100526

Vangompel ECW, Franks P, Robbins JA, Fenton JJ (2017): Incidence and predictors of repeat bone mineral densitometry: a longitudinal cohort study. J. Gen. Intern. Med. 32, 1090-1096 https://doi.org/10.1007/s11606-017-4094-y

Vickers MH (2014): Developmental Programming and Transgenerational Transmission of Obesity. Ann. Nutr. Metab. 64, 26-34 https://doi.org/10.1159/000360506

Yarrow JF, Toklu HZ, Balaez A, Phillips EG, Otzel DM, Chen C, Wronski TJ, Aguirre JI, Sakarya Y, Tümer N (2016): Fructose consumption does not worsen bone deficits resulting from high-fat feeding in young male rats. Bone 85, 99-106 https://doi.org/10.1016/j.bone.2016.02.004

Yeap BB, Alfonso H, Chubb SP, Gauci R, Byrnes E, Beilby JP, Ebeling PR, Handelsman DJ, Allan CA, Grossmann M (2015): Higher serum undercarboxylated osteocalcin and other bone turnover markers are associated with reduced diabetes risk and lower estradiol concentrations in older men. J. Clin. Endocrinol. Metab. 100, 63-71 https://doi.org/10.1210/jc.2014-3019

Received: January 10, 2019

Final version accepted: July 2, 2019

First published online: August 14, 2019 
Supplementary Material

\title{
The potential developmental programming effect of oral curcumin on the bone health and plasma total osteocalcin of male and female rats fed a high-fructose diet during suckling and post weaning
}

\author{
Kasimu G. Ibrahim ${ }^{1,2}$, Hayley L. Wright ${ }^{1}$, Eliton Chivandi ${ }^{1}$, Michael T. Madziva ${ }^{1}$ and Kennedy \\ H. Erlwanger ${ }^{1}$ \\ ${ }^{1}$ School of Physiology, Faculty of Health Sciences, University of the Witwatersrand, Johannesburg, South Africa \\ ${ }^{2}$ Department of Physiology, Faculty of Basic Medical Sciences, College of Health Sciences, Usmanu Danfodiyo Uni- \\ versity, Sokoto, Nigeria
}

Table S1. Effect of fructose administration on fasting blood glucose and insulin of adolescent male Sprague Dawley rats that were administered with curcumin during suckling

\begin{tabular}{lcc}
\hline Group & $\begin{array}{c}\text { Fasting blood glucose } \\
(\mathrm{mmol} / \mathrm{l})\end{array}$ & $\begin{array}{c}\text { Insulin } \\
(\mathrm{nmol} / \mathrm{l})\end{array}$ \\
\hline DMSO+TW & $4.10 \pm 0.18$ & $0.08 \pm 0.02$ \\
DMSO+FW & $4.50 \pm 0.20$ & $0.07 \pm 0.02$ \\
CC+TW & $3.90 \pm 0.04$ & $0.09 \pm 0.02$ \\
CC+FW & $4.00 \pm 0.12$ & $0.08 \pm 0.02$ \\
FW+TW & $4.50 \pm 0.25$ & $0.06 \pm 0.01$ \\
FW+FW & $4.00 \pm 0.10$ & $0.11 \pm 0.02$ \\
CCFW+TW & $4.40 \pm 0.30$ & $0.09 \pm 0.02$ \\
CCFW+FW & $4.40 \pm 0.20$ & $0.08 \pm 0.02$ \\
\hline
\end{tabular}

There were no differences $(p>0.05)$ in the fasting blood glucose and plasma insulin concentration of the rats across the treatment groups. $\mathrm{DMSO}+\mathrm{TW}=10 \mathrm{ml} / \mathrm{kg}$ of a $0.5 \%$ dimethyl sulfoxide solution as neonates and plain tap water post weaning, $\mathrm{DMSO}+\mathrm{FW}=10 \mathrm{ml} / \mathrm{kg}$ of a $0.5 \%$ dimethyl sulfoxide solution as neonates and fructose $(20 \%$, $\mathrm{w} / \mathrm{v})$ as drinking fluid post weaning, $\mathrm{CC}+\mathrm{TW}=$ Curcumin $(500 \mathrm{mg} /$ $\mathrm{kg}$ in $0.5 \% \mathrm{DMSO}$ ) as neonates and plain tap water post weaning, $\mathrm{CC}+\mathrm{FW}=$ Curcumin $(500 \mathrm{mg} / \mathrm{kg}$ in $0.5 \% \mathrm{DMSO})$ as neonates and fructose $(20 \%, \mathrm{w} / \mathrm{v})$ as drinking fluid post weaning, $\mathrm{FW}+\mathrm{TW}=$ fructose $(20 \%, \mathrm{w} / \mathrm{v})$ as neonates and plain tap water post weaning, $\mathrm{FW}+\mathrm{FW}=$ fructose $(20 \%, \mathrm{w} / \mathrm{v})$ as neonates and fructose $(20 \%, \mathrm{w} / \mathrm{v}$ ) as drinking fluid post weaning, CCFW+TW = curcumin $(500 \mathrm{mg} /$ $\mathrm{kg}$ ) and fructose $(20 \%, \mathrm{w} / \mathrm{v})$ in $0.5 \%$ DMSO as neonates and plain tap water post weaning, $\mathrm{CCFW}+\mathrm{FW}=$ curcumin $(500 \mathrm{mg} / \mathrm{kg})$ and fructose $(20 \%, \mathrm{w} / \mathrm{v})$ in $0.5 \% \mathrm{DMSO}$ as neonates and fructose $(20 \%$, w/v) post weaning. Data expressed as mean \pm SEM, $n=7-9$ per group.

Correspondence to: Kasimu Ghandi Ibrahim, Department of Physiology, Faculty of Basic Medical Sciences, College of Health Sciences, Usmanu Danfodiyo University, P.M.B. 2254, Sokoto, Nigeria E-mail: ghandi.kasimu@udusok.edu.ng
Table S2. Effect of a high fructose diet on fasting blood glucose and insulin of female Sprague Dawley rats that were administered with curcumin during suckling

\begin{tabular}{lcc}
\hline Group & $\begin{array}{c}\text { Fasting blood glucose } \\
(\mathrm{mmol} / \mathrm{l})\end{array}$ & $\begin{array}{c}\text { Insulin } \\
(\mathrm{nmol} / \mathrm{l})\end{array}$ \\
\hline DMSO+TW & $4.30 \pm 0.20$ & $0.08 \pm 0.02$ \\
DMSO+FW & $4.30 \pm 0.16$ & $0.10 \pm 0.02$ \\
CC+TW & $4.30 \pm 0.10$ & $0.09 \pm 0.02$ \\
CC+FW & $3.90 \pm 0.16$ & $0.08 \pm 0.02$ \\
FW+TW & $3.90 \pm 0.29$ & $0.06 \pm 0.01$ \\
FW+FW & $4.00 \pm 0.10$ & $0.08 \pm 0.02$ \\
CCFW+TW & $4.20 \pm 0.12$ & $0.08 \pm 0.02$ \\
CCFW+FW & $4.00 \pm 0.12$ & $0.11 \pm 0.02$ \\
\hline
\end{tabular}

There were no differences $(p>0.05)$ in the fasting blood glucose and plasma insulin concentration of the rats across the treatment groups. DMSO+TW $=10 \mathrm{ml} / \mathrm{kg}$ of a $0.5 \%$ dimethyl sulfoxide solution as neonates and plain tap water post weaning, $\mathrm{DMSO}+\mathrm{FW}=10 \mathrm{ml} / \mathrm{kg}$ of a $0.5 \%$ dimethyl sulfoxide solution as neonates and fructose $(20 \%$, $\mathrm{w} / \mathrm{v})$ as drinking fluid post weaning, CC+TW = Curcumin $(500 \mathrm{mg} /$ $\mathrm{kg}$ in $0.5 \% \mathrm{DMSO}$ ) as neonates and plain tap water post weaning, $\mathrm{CC}+\mathrm{FW}=$ Curcumin $(500 \mathrm{mg} / \mathrm{kg}$ in $0.5 \% \mathrm{DMSO})$ as neonates and fructose $(20 \%, \mathrm{w} / \mathrm{v})$ as drinking fluid post weaning, $\mathrm{FW}+\mathrm{TW}=$ fructose $(20 \%, \mathrm{w} / \mathrm{v})$ as neonates and plain tap water post weaning, $\mathrm{FW}+\mathrm{FW}=$ fructose $(20 \%, \mathrm{w} / \mathrm{v})$ as neonates and fructose $(20 \%, \mathrm{w} / \mathrm{v}$ ) as drinking fluid post weaning, CCFW+TW = curcumin $(500 \mathrm{mg} /$ $\mathrm{kg}$ ) and fructose (20\%, w/v) in $0.5 \%$ DMSO as neonates and plain tap water post weaning, CCFW+FW = curcumin $(500 \mathrm{mg} / \mathrm{kg})$ and fructose $(20 \%, \mathrm{w} / \mathrm{v})$ in $0.5 \% \mathrm{DMSO}$ as neonates and fructose $(20 \%$, $\mathrm{w} / \mathrm{v})$ post weaning. Data expressed as mean $\pm \mathrm{SEM}, n=7-9$ per group.

The fasting blood glucose concentration of the rats was determined using a calibrated glucometer (Contour Plus ${ }^{\mathrm{TM}}$, Bayer Corporation, Mishawaka, USA) while the fasting plasma insulin was determined using an enzyme-linked immunosorbent assay (ELISA) kit [Elabscience ${ }^{\circledR}$ INS (Insulin) ELISA kit, Houston, TX, USA] according to the manufacturer's instructions. 